\title{
Studying the sensitivity of GOCE gravity gradients to the crustal structure: case study of Central Europe
}

\author{
Artur Lenczuk $^{1}$ (D) . Janusz Bogusz ${ }^{1}$ (D) . Tomasz Olszak ${ }^{2} \cdot$ Marcin Barlik $^{2}$
}

Received: 13 May 2018 / Accepted: 28 January 2019 / Published online: 5 February 2019

(c) The Author(s) 2019

\begin{abstract}
We discuss the determination of gravity gradients from the orbital ceiling to the depth of the Mohorovičić discontinuity (Moho) for Central Europe. Components of the Eötvös tensor were derived from "Heterogeneous gravity data combination for Earth interior and geophysical exploration research" project ("GOCE+") by using the gridded data with a resolution of $0.2^{\circ}$ per $0.2^{\circ}$. Gravity gradients to Moho boundary depth were modelled forward to the $255 \mathrm{~km}$ orbital height. We calculated gradient sensitivity using a 3D model divided into: sediments and consolidated crust including the precise location of the Moho boundary. To define tesseroids as mathematical model we need to set two parameters of the crust: density and thickness for each spherical layer separately. Altitudes for topography/bathymetry were derived from ETOPO1 model, sediments thickness from EuCRUST-07 model, and Moho boundary from Grad and Tiira (Geophys J Int 176(1):279-292, 2009. https://doi. org/10.1111/j.1365-246x.2008.03919.x) seismic map. For high latitudes, we noted the largest changes for the gradients towards the poles, with particular values of $689.07 \mathrm{mE}$ (millieotvos) and $1138.19 \mathrm{mE}$ for $V_{X X}$ and $V_{Z Z}$ gradients, respectively. We obtained extreme values for the location of the deep and shallow areas of the crust (Alps, North-Eastern Poland and areas of seas) equal to $-3 \mathrm{E}$ and $+1.5 \mathrm{E}$, respectively. Most of the gradients showed strong correlation with anomalies in crustal density of $-2.5 \mathrm{E}$ for $V_{Z Z}$ and $+1.5 \mathrm{E}$ for $V_{Y Y}$ in the extreme cases. We showed that changes in crust density and thickness by respectively $50 \mathrm{~kg} / \mathrm{m}^{3}$ and $10 \mathrm{~km}$ entail changes in gradient values by $15 \%$ for density and $10 \%$ for depths. Numerical analysis considering Preliminary Reference Earth Model (PREM) showed importance of density modeling for determination of gravity gradients.
\end{abstract}

Keywords GOCE · Tesseroid · Eötvös tensor · Mohorovičić discontinuity · Gradiometry

Artur Lenczuk

artur.lenczuk@wat.edu.pl

1 Faculty of Civil Engineering and Geodesy, Military University of Technology, Warsaw, Poland

2 Faculty of Geodesy and Cartography, Warsaw University of Technology, Warsaw, Poland 


\section{Introduction}

The Gravity Field and Steady-State Ocean Circulation Explorer (GOCE; Rummel 2011) was the first gravity satellite mission implement by the ESA (European Space Agency), which provided data from November 2009 till October 2013 (Arabelos and Tscherning 1998; Rudolph et al. 2002; Bobojc 2016). The aim of the mission was to determine the Earth's mean gravity field with high accuracy at a spatial resolution of $100 \mathrm{~km}$ or better (Albertella et al. 2002; Bouman et al. 2009; Rummel et al. 2011a; Peral et al. 2018). GOCE was the first satellite ever that measured gravity gradients in space with gradiometer (Bouman and Koop 2003), which was the major satellite instrument. Additionally, GOCE satellite carried the satellite-to-satellite tracking (SST) instrument that was used to determine the position and velocity of the satellite. The SST instrument is more accurate at lower, while the gradiometer is more accurate at higher spatial resolutions (Siemes 2017). The gradiometer was realized by an ensemble of six three-axes accelerometers in the so-called diamond configuration being able to determine the gravity gradients in the six reference frames (Arabelos and Tscherning 1998), with a composition accuracy depending on the type of gravitational gradient being expressed in Gradiometer Reference Frame (GRF), which is a rotating instrument frame (Bouman et al. 2011). Four (namely, $V_{X X}, V_{Y Y}, V_{Z Z}$ and $V_{X Z}$ ) of six Eötvös tensor components expressed in the GRF have much higher accuracy $\left(1-2 \mathrm{mE} / \mathrm{Hz}^{0.5}\right.$, eotvos means $10^{-9} 1 / \mathrm{s}^{2}$ ) in the Measurement Bandwidth (MBW), while the remaining $V_{X Y}$ and $V_{Y Z}$ components do not, and their errors have a larger magnitude than for the other gradients (Bouman and Koop 2003). It's a near 2-3 orders equal $1 \mathrm{E} /$ $\mathrm{Hz}^{0.5}$ (Rummel et al. 2011a, b) and it may contain systematic errors. The MBW responds to spatial resolution of 40-750 km half-wavelengths (Bouman et al. 2016). The gradients may also be expressed in the topocentric Local North-Oriented Frame (LNOF), with the LNOF gradients being a compromise between easiness to interpret and keeping as much as possible the original GOCE data. Thus it is not straightforward to use the gradients in the GRF, it is better if gravity gradients are transformed into LNOF. During transformations between gradiometer and topocentric frames the gaps in MBW are filled with data from the gravity field models. In most cases the LNOF is applied to study the properties of the lithosphere (e.g. Ebbing et al. 2013). In this research we also choose to use LNOF frame, which will not be singular when calculating GRF components from a gravity spherical harmonics model (Eshagh 2008). Additionally, the GRF is symmetric and the trace of the GRF equals zero. Hence, there are only five independent GRF components (Zhang et al. 2018).

The GOCE-driven gravimetric data have many possible applications. Firstly, it is feasible to provide a gravity field with $80 \mathrm{~km}$ resolution (Bouman et al. 2011). Secondly, the GOCE mission reduced measurements provide gravity gradients, which may be applied to determine gravity field models, which can be then used for global Mohorovičić (Moho) discontinuity depth estimates (Sjöberg and Bagherbandi 2011) or linked with data from other missions (Gilardoni et al. 2016). Less often, these data are developed into spherical harmonics. However, the gradients are more convenient to be used rather than spherical harmonics, because of a priori information taken and/or global regularization (Bouman et al. 2013). Further, gravity gradients data are generally sensitive to shallower structures than the gravity field main part and provide information about the variations in the gravity field in both: horizontal and vertical directions (Ebbing et al. 2014). In the previous studies, gradients were used to study Earth's crust properties (Ebbing et al. 2014), such as the Moho boundary depth: for the entire globe (Reguzzoni and Sampietro 2014) or smaller areas such as the central part of Eurasia (Eshagh et al. 2016). The gravity field anomalies 
may be used for similar goals. For example, Tenze et al. (2014) calculated the thickness of the Earth's crust in North-Eastern Pakistan, while Braintenberg (2015) identified tectonic structures with GOCE data in Africa and across-continents. Furthermore, the gradients from the gravimetric satellite mission can be combined with other data, e.g., altimetric to study the changes occurring not only in the solid Earth structures, but also in glaciers (Rummel et al. 2011a), atmosphere (Garcia et al. 2016; Liu et al. 2016) and ocean circulations (Sanchez-Reales et al. 2016).

In this paper, we dealt with problems of the optimal selection of the crust's density and the location of the Moho boundary to reduce the gradients obtained from GOCE to the assumed depth. We used tesseroids as the mathematical model to determine six gravity gradients in the LNOF frame. Tesseroids are a volume elements defined on the sphere by two meridians, two parallels and two radius-vectors of a given resolution, expressed in the global or local frame, previously used for investigation of the Earth's gravity field e.g. by Grombein et al. (2013) or Marotta and Barzaghi (2017). After assigning density to each tesseroid, we are able to compute gravitational potential, gravity and gravity gradients. In our research we defined the tesseroids with the horizontal resolution of $0.2^{\circ}$ per $0.2^{\circ}$ with the thickness taken from each considered layer of the Earth. Then, we used such constructed tesseroids to reduce GOCE gradients, being with a strong relation to the geological structure of the crust, mainly density, thickness as well as the height of the reference surface.

Investigation of effect of different heights of the reference surface on the determined gradients was one of the goals of the "GOCE+" project, supported by the European Space Agency (ESA) revealing an impact of 1 E per $50 \mathrm{~km}$ (Bouman et al. 2013). "GOCE+" was an international project carried out by a group of scientists from Germany, Norway and the Netherlands. The project's purpose was also a combination of GOCE gravity gradients with other data to get a grouping set of gravity gradients expanding (near-)surface information spanning all scales from global down to $5 \mathrm{~km}$. The "GOCE+" data cover the time span from 1st February 2010 to 11th November 2013, they were filtered (Schuh 2003) and reduced with GOCO03s model values (Mayer-Guerr et al. 2012). In our research, we used data from GOCE gravimetric mission, reduced to WGS84 ellipsoid. The effect of topography was previously removed within GOCE+ project by the RWI_TOPO_2012 model (Grombein et al. 2014) for rock, water and ice density. RWI_TOPO_2012 is a spherical harmonics model complete to degree and order 1800 with a three-layer decomposition of the topography using DTM2006.0 database being applied. To obtain topographic mass reduction, density for rock, water and ice was modelled with specific values of $2670 \mathrm{~kg} / \mathrm{m}^{3}$, $1000 \mathrm{~kg} / \mathrm{m}^{3}$ and $920 \mathrm{~kg} / \mathrm{m}^{3}$ (Bouman et al. 2016), respectively.

With this type of satellite data it is possible to study the Moho boundary, with a density contrast up to $600 \mathrm{~kg} / \mathrm{m}^{3}$ over a few kilometers being noticed (Ebbing et al. 2014). The research of modelling depth slices to the Moho boundary was previously conducted for the North-Eastern Atlantic margin obtaining gradients sensitivity of \pm 1 E (Bouman et al. 2013).

Prior studies focused on assessing the sensitivity of GOCE gravity gradient to geological structures with respect to depth of their location (Bouman et al. 2013) or comparing gradient signal measured at the orbital altitude with gradients related to density contrast between crust and mantle. In our study, we focused on implementing the recent models of crust's density and thickness in order to obtain the most reliable values of gravity gradients to the assumed location of the Moho discontinuity. For this purpose, we examined the area of Europe, which is geologically diverse and is characterized by a relatively high contrast of depth on small area and various geological structural units. A particular area of research is Central Europe, where 
three geological units meet: the Eastern European, Paleozoic and Alpine platforms. The first two platforms differ significantly in terms of the thickness of sediments and properties of the crust with the Trans European Suture Zone (TESZ). The Eastern European's substrate is composed of pre-Cambrian metamorphic and magma rocks while the area of the Paleozoic platform is covered with a thick series of Permian-Mesozoic and Cenozoic deposits (Narkiewicz and Petecki 2017).

The main idea of this research is to investigate the sensitivity of gravitational gradients determined from the satellite's altitude to several kilometers into the Earth's interior, and to get the highest possible reliability for data being possibly compared in the future to the terrestrial measurements. Bouman et al. (2013) showed that the distinguished differences of gravity gradients are occurred due to the Earth's structure up to $\pm 1 \mathrm{E}$ to $125 \mathrm{~km}$ depth and smaller values equal $\pm 0.2 \mathrm{E}$ to $175 \mathrm{~km}$ below the surface. Tenzer and Novák (2013) provided a map for radial $(r r)$ and two horizontal $(\varphi \varphi$ and $\lambda \lambda)$ gradient components, obtaining $\pm 1.5 \mathrm{E}$ for the entire world. They calculated the gravity gradients and removed the effects of topography, bathymetry, ice, sediments and crust by forward modelling from an altitude of $255 \mathrm{~km}$. Eshagh et al. (2017) used the GOCE data in the opposite way, comparing Sjöberg and Jeffrey's methods to determine the Moho boundary depth, which was reduced by topography/bathymetry corrections, effect of sediments and compensation attraction for Iran area. For the same region, Bagherbandi and Eshagh (2012) set the Moho boundary based on the theory of Vening Meinesz-Moritz and the gradiometric GOCE data. Shin et al. (2015) performed similar studies comparing the difference of the location of Moho discontinuity on the gravity field models with GOCE data. Eshagh et al. (2016) conducted research on sub-lithospheric stresses, using the combination of GOCE data, the crustal seismic model with CRUST1.0 (Laske et al. 2013) and the data from the Shuttle Radar Topography Mission (SRTM). Bouman et al. (2013) performed research for North Atlantic area examined the dependence of gradients by measuring height and density of subsurface down to the Moho discontinuity. They assessed the sensitivity of the GOCE gravity gradient data to geological structures with respect to their thickness and relative density contrast studied at orbital altitude from Moho boundary.

Our research is focused on determining the values of gravity gradients reduced from the satellite altitude down to the Moho layer by modelling two parameters of the crust: density and thickness. Two layers of crust were distinguished, according to the Molinari and Morelli (2011) concept. They proposed to divide the crust into sediments as well as upper and lower consolidated crust together to the Moho discontinuity's depth. The model based on this approach will be denoted in the following parts of this paper as a "3D model". The research consists of eliminating the influence of each layer on the GOCE data depending on the various method of density and depth modeling, in contrast to the others who analyzed how modeling of the crustal structure on a regional scales is affected by uncertainties in the deeper structure (upper mantle) (Ebbing et al. 2014).

This paper is organized as follows. In Sect. 2 we describe the data and the methods used for each step of analysis, the provided 3D model for Central Europe is shown in Sect. 3. In Sect. 4 we discuss the results of the study by providing additional numerical analysis, which will be summarized in Sect. 5. 


\section{Data sets and methods}

The research area covers a large part of Europe extending from the West coast of Spain to Western Russia $\left(10^{\circ} \mathrm{W}-36^{\circ} \mathrm{E}\right)$ and from the Mediterranean to Northern Scandinavia $\left(40^{\circ} \mathrm{N}-70^{\circ} \mathrm{N}\right)$. Firstly, we divide the crust into two layers: sedimentary and consolidated crust. For each layer we used the densities and thicknesses from various models and methods, which allowed us to get as reliable results as possible. The used methods will be described in the following subsections. The gravitational effects of consolidated crust and sedimental layer were calculated using the open-source software Tesseroids (Uieda et al. 2016), providing six components of the Eötvös tensor. We adopted tesseroids' size with a lateral resolution of $0.2^{\circ}$ per $0.2^{\circ}$. For each layer, we defined reference level. In case of sediments we assumed mean sea level $(0 \mathrm{~km})$ while for consolidated crust the assumed reference levels define the characters of the determined gradients. This means, if the tesseroid is below the reference level, the density value is negative, otherwise it is positive. So we must focus on thicknesses adopted and the fact that we get contrasts in the density between the individual depths, on which the gradients are more sensitive. We assumed a depth of $32 \mathrm{~km}$, similar to Bouman et al. (2013), due to the fact that the median depth of the Moho discontinuity determined for the considered by us area is equal to $32.5 \mathrm{~km}$. The gradients were calculated at a height of $255 \mathrm{~km}$ above the ellipsoid [the average altitude of the GOCE satellite orbit (Bouman and Koop 2003; Bouman et al. 2009; Bobojc 2016)]. After calculating the sediments and consolidated crust effects, all values were summed up to obtain gradients from the height of $255 \mathrm{~km}$ above the ellipsoid to the depth of the Moho boundary. The effects of sedimentary and consolidated crust layers were determined separately by methods, which are described in Table 1 and discussed in subsequent sections.

Finally, to examine the sensitivity of gradients to the change of the adopted model, we have calculated the gradients for both layers using the density defined by the Preliminary Reference Earth Model (PREM; Dziewonski and Anderson 1981). With this investigation we would like to show the essence of proper selection of the density model, since too general model may simplify calculated gradients and disturb the final findings too much. The PREM is a 1-D model consisting of a dataset representing the Earth's average properties (density, depth, longitudinal and transverse waves) as a function of its radius. Since the changes of gradients for the whole area are very approximate, we are not able to distinguish density and depth-caused anomalies, we used PREM just for discussion of the results presented in last paragraph.

Table 1 Assumptions for modelling of the crust and main references for each layer

\begin{tabular}{|c|c|c|c|c|}
\hline \multirow{2}{*}{ Layer } & \multicolumn{2}{|l|}{ Depth } & \multicolumn{2}{|l|}{ Density } \\
\hline & Model & References & Model & References \\
\hline Consolidated crust & Digital model & Grad and Tiira (2009) & Density function & $\begin{array}{l}\text { Yegorova and Starostenko } \\
\text { (2002) }\end{array}$ \\
\hline Sediments & EuCRUST-07 & Tesauro et al. (2008) & Density function & $\begin{array}{l}\text { Yegorova and Starostenko } \\
\text { (2002) }\end{array}$ \\
\hline
\end{tabular}




\subsection{Sedimentary layer}

Within this research we provided a separate models for the sedimentary layer based on the definition of density and thickness. Presently, there are several global models defining the depth of the sediments [e.g. CRUST1.0 and CRUST2.0-Tsoulis (2004)]. We used the model presented by Yegorova and Starostenko (2002) for the European areas. For this layer, the calculations focused only on determining the contrast dependence of density relative to density on mean sea level (reference level) equals $1900 \mathrm{~kg} / \mathrm{m}^{3}$. The density contrast was calculated on resolution of $1 \mathrm{~km}$ depth relative to reference level obtaining values within the range of $0-700 \mathrm{~kg} / \mathrm{m}^{3}$. We calculated the density contrast, because gravity measurements are more sensitive to their differences (contrast), rather than absolute values (Bouman et al. 2013; Eshagh et al. 2016). Then, we took the values from the EuCRUST-07 model (Tesauro et al. 2008) for thickness of the sedimentary layer. EuCRUST-07 model contains also the values of seismic waves velocity, topography (ETOPO2), and the depth of Moho boundary. The original data is gridded of $0.25^{\circ}$ per $0.25^{\circ}$, so we performed the linear interpolation to the $0.2^{\circ}$ per $0.2^{\circ}$ grid. In case of the thickness of sedimentary layer, the values ranged from $1.22 \mathrm{~km}$ above to a depth of $15 \mathrm{~km}$ below the sea level. Analyzing the data, it can be noticed that sediment densities vary by a maximum of $700 \mathrm{~kg} / \mathrm{m}^{3}$ (oceancontinent contrast) for the entire study area. Those findings are quite similar to the results of Yegorova and Starostenko (2002) for the general distribution of sludge density under the surface. The largest density diversity is visible in the central part of the studied area (Poland), where two geological structures meet: the East European Craton and the Paleozoic Platform, separated by the Teisseyre-Tornquist Zone (Znosko 1977). However, we are aware that the distribution of sediments density under the surface depends mainly on the tectonic setting and climatic conditions that affects their environment deposition (e.g. size and type of grain components and their origin) and the thickness of the sedimentary layer.

\subsection{Consolidated crust layer}

The next distinguished layer of the crust is a layer extending from the lower level of the sediments to the Moho boundary (consolidated crust layer), where the radical changes in seismic velocity and density are observed. Several models and software were provided to analyze the Moho boundary depth. One of them is the LitMod3D (Fullea et al. 2009), which delivers the information on the velocity of seismic waves and physical properties of geological structures, other are GEMMA (Reguzzoni and Sampietro 2014) and M7 (Meier et al. 2007). In this research, we used the Moho discontinuity depth from Grad and Tiira (2009), who provided the first digital map developed for the whole European plate, being recently the most accurate depth model for Europe. It was compiled from more than 250 data sets of individual seismic profiles, 3D models obtained by observation of a body and surface waves, receiver function results, and gravity data compilations. For modeling the density, we used the model presented by Yegorova and Starostenko (2002), which provides the values of the density of subsurface units depending on their depth. In our study, we attributed the densities for the shell layers every $2 \mathrm{~km}$ deep above $32 \mathrm{~km}$ and every $5 \mathrm{~km}$ below $32 \mathrm{~km}$ from Yegorova and Starostenko's model. Consequently, the change in density contrast was examined in relation to the adopted density references to a depth of $32 \mathrm{~km}$ (Bouman et al. 2013), assigning a positive value of density to the shallower masses than the reference level and a negative for deeper ones. Finally, we summed up influences 
of the both layers with GOCE+ gradients obtaining the model of values of Eötvös tensor components.

\section{The model}

All effects of sedimentary and consolidated crust, described in the previous section, were expressed in the topocentric frame (LNOF), after the transformation from GRF. Unfortunately, this transformation may cause discrepancies in the gradients values (especially on $V_{X Y}$ and $V_{Y Z}$ components), so during the interpretation one must be careful since it may cause a bad reading (Bouman et al. 2013). In the first step, we reduced the values of gradients due to effect of sediments. In this case instead of absolute values, we calculated the density contrast relative to the reference density value on the mean sea level (equal to $1900 \mathrm{~kg} / \mathrm{m}^{3}$ ) and depth taken from the EuCRUST-07 model. Then, using the Tesseroids software, we determined the gravity gradients. The smallest variations were obtained for the $V_{X Y}$ and $V_{Y Y}$ components equal to 155.63 and $258.06 \mathrm{mE}$, respectively. It confirms that the $X Y$ component is the least sensitive to the change in the properties of geological structures. The $V_{Z Z}$ component is the most sensitive to the mass distribution in subsurface structures, but also to the errors caused during transformation due to the largest rotation around $Z$ axis between the GRF and LNOF (Bouman et al. 2011). It is very clear that extreme values occur for all components in areas of specific topography: the Scandes, the Carpathians, the Baltic Sea and the Atlantic Ocean in our case study.

Then, we determined the effect on gradients for the consolidated crust layer. We also analyzed the values of gradients for Moho border depth without subtracting the thickness of the sediments. The values of the gradients obtained in this way differ by hundreds of $\mathrm{mE}$, which indicates a small effect of the change in thickness of tesseroids on the determined gradients. The deepest border of Moho is located in the vicinity of the Alps, South Finland and the North-East of Poland, where the isobates exceed $45 \mathrm{~km}$, with maximum in Finland $(59.8 \mathrm{~km})$. On the other hand, Moho's shallowest location occurs at $11.8 \mathrm{~km}$ in ocean. In consolidated crust layer, density was determined as a contrast reference density equal to $2700 \mathrm{~kg} / \mathrm{m}^{3}$ in relation to the surface taken at a depth of $32 \mathrm{~km}$. We obtained gradients standard deviation on the examined area equal to 49.42, 82.74 and $106.64 \mathrm{mE}$ for $V_{X X}, V_{X Y}$ and $V_{X Z}$, respectively with $V_{Z Z}$ being characterized by the greatest diversity.

Finally, calculated effects for both layers were summed up obtaining the forward modeled gradients from $255 \mathrm{~km}$ GOCE altitude to the Moho border depth, providing the 3D model of second potential derivatives with a resolution of $0.2^{\circ}$ per $0.2^{\circ}$ (Fig. 1). As was previously noted, each gradient has different directional sensitivity. For example, the $V_{X X}$ component is sensitive to north-south oriented structures, opposite to $V_{Y Y}$ (Fig. 1). The radial pointing $V_{Z Z}$ gradient is isotropic as the Laplace equation holds $\left(V_{Z Z}=-V_{X X}-V_{Y Y}\right)$, and thus includes the strongest gravitational signal, which also can be easily noticed in Fig. 1.

Gradient values behave homogeneously outside the areas of specific geological structures for all cases, even for $V_{X Y}$ component, which is a constituent of the shape and is poorly determinable in LNOF. On the map of this component we can recognize the TESZ zone (the structure from North-Eastern Poland to Romania), which we can be also seen on another shape component $V_{Y Z}$ (white pattern). Both gradients are the weakest in the MBW frequency, although they are also sensitive to changes in the crust parameters to the depth of Moho discontinuity. The changes for the $V_{X X}, V_{Y Y}$ and $V_{Z Z}$ components are clearly 

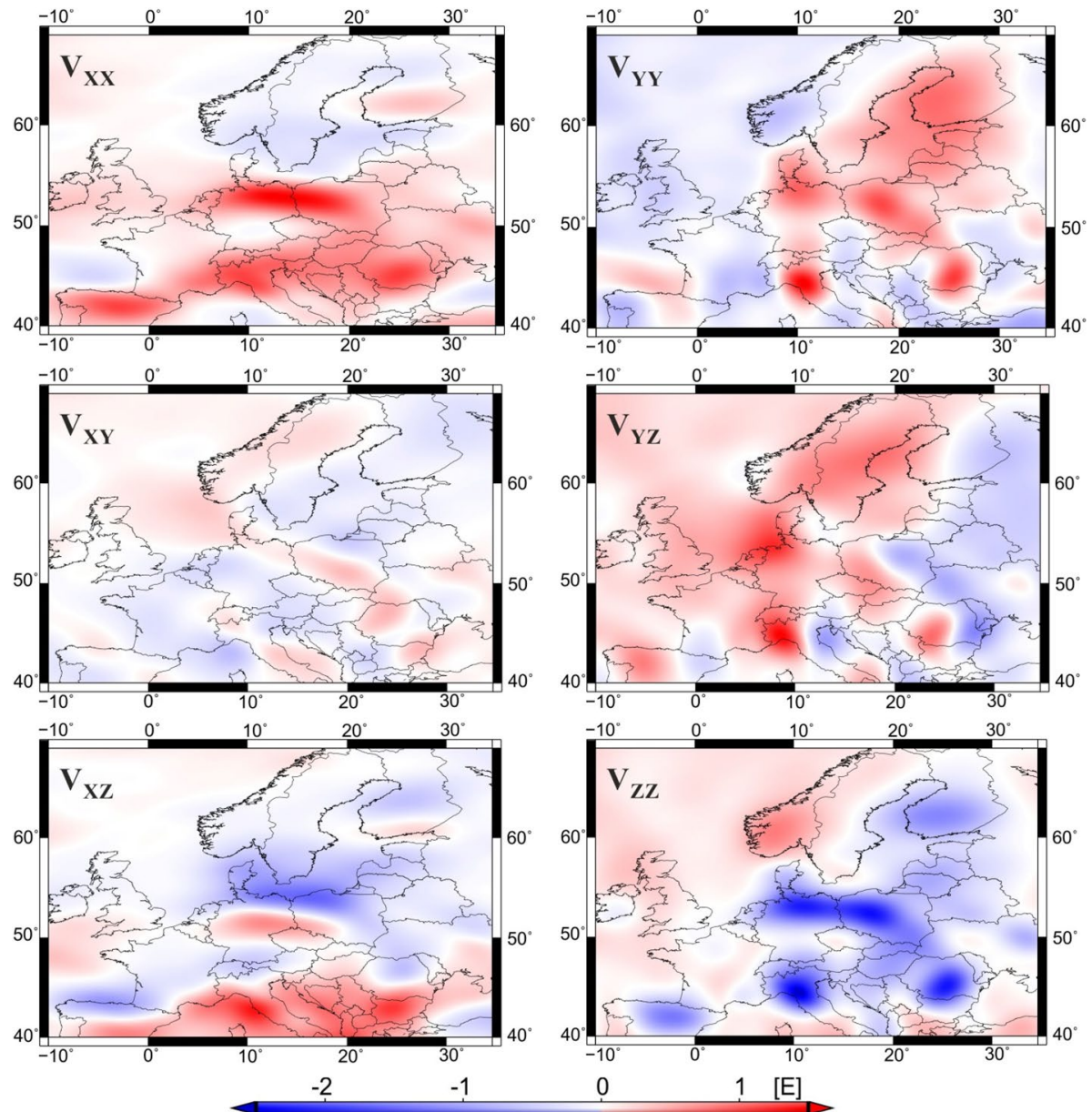

Fig. 1 The values of second potential derivatives for the Central Europe obtained from the GOCE missions reduced (density and thickness) by the sediments and consolidated crust layers. Values presented in the LNOF frame from altitude of $255 \mathrm{~km}$, expressed in [E] (eotvos)

visible, with the first two having the smallest magnitudes, in turn the $V_{Z Z}$ has the biggest. Places of extreme values (red and blue colors) coincide with the thick and thin consolidated crust and sedimentary layers. In particular, the areas of thickest crust corresponding to the Alps, Baltic Shield (Southern Finland), and Moesian Platform (Romania), are characterized by negative $V_{Z Z}$ component and positive gradients for all the other components and displayed as blue and red areas, respectively. Similarly to the crust, the area of thickest sedimental layer agreeing with the North German-Polish Basin, are marked by negative gradients for $V_{Z Z}$ component and positive gradients for all the other components (Fig. 1). Same as Rummel et al. (2011b), we can list the two most distinct areas, especially visible for the $V_{Z Z}$ gradient. These are: the Alps and North German-Polish Basin and less visible the south part of Baltic Shield (South Norway and South Sweden). This characteristic may be further emphasized by the values of gravimetric anomalies calculated by subtracting the normalized effect of total gravity for the model from the observed gravity field. Gravity 
anomalies indicate different areas, i.e. part of Russian Platform (Lithuania/Belarus) and the Alps, where anomalies take negative values in the vicinity of positive anomalies and double values of anomalies for the surface of Atlantic Ocean (see Yegorova and Starostenko 2002 for more details). The Baltic Sea is not clearly marked due to its shallownessaverage depth $52.3 \mathrm{~m}$ (Heyen et al. 1996). When focusing only on North-Eastern Atlantic margin, we observe gradient values similar to the results presented in Bouman et al. (2013) for the Moho border depth of 30-35 km as the changing of plus/minus values line on Norway and Sweden area, marked on $V_{Y Y}$ and $V_{Z Z}$ components maps. We also noticed maximum values on central Sweden and north part of Germany for $V_{Y Z}$ component as well as the diversity of gradients values between $55^{\circ}$ and $70^{\circ}$ meridians in similar range of $\pm 1 \mathrm{E}$. Additionally, in the North-Eastern Atlantic region, we may notice the strong regional variations in the geoid (Bouman et al. 2013) and gravity field clearly seen for $V_{Y Y}$ and smaller $V_{Z Z}$ components presented by blue values (Precambrian shields-Baltic Shield) and red area (deep oceanic/sea crust-Scandinavia mountains). However, Bouman et al. (2013) results are not comparable to the results presented in this study in the direct sense, because they investigated what kind of a gravity gradient signal may be expected at satellite altitude from the Moho border, while we just confirmed the possibility of obtaining gradients with high reliability. The highest frequency noise remains on the $V_{Z Z}$ component, what cause the greatest variability for this derivative for all considered layers. On the other hand, the large spread of the $V_{X X}$ component value is caused by the highest amount of data, which was taken from the gravity field models to fill in the gaps in the GOCE mission data. The accuracy of gravity gradients increases for lower frequencies (Bouman et al. 2011), so the measured frequency signals are replaced by model signals. Figure 1 shows that all gradients are characterized by positive values on ocean area, except $V_{Y Z}$ component. The $V_{X Y}$ and $V_{Y Z}$ components are the least variable and characterized by the smallest various (pale colors), but only these components distinguish the TESZ zone significantly.

\section{Numerical analysis}

The gravity gradients derived from the 3D model (sedimentary and consolidated crust layers) were compared to those determined from a generalized model based on the density distribution from the PREM, which was developed under the linear relationship between densities and the Earth's radius, with tesseroids differing by a thickness of several kilometers and described by the same density. In our study, we used two different density models to assess the change of gravity gradients caused by increasing the reliability of density, exhibiting their sensitivity even at the satellite attitude. We used the density model based on PREM as a reference and we implemented a 3D density model being more sophisticated, to compare the obtained results. Therefore, for both density models (PREM and 3D model), we set the density contrasts with respect to $0 \mathrm{~km}$ for the sedimentary layer and depth equal $32 \mathrm{~km}$ for consolidated crustal layer, which we used to calculate the spatial changes of gravity gradients. Finally, as a result, we obtained the values of gradients that differ significantly in each component (Fig. 2 and Table 2). In this way, we indicate a significant sensitivity of gradients to the change of the density and depth parameters. From Table 2 we can notice, that average magnitudes of differences have increased few times comparing to the values for 3D model and equal to $0.69,0.11,-0.24,0.64,-0.30$ and $-1.33 \mathrm{E}$ for $V_{X X}, V_{X Y}$, $V_{X Z}, V_{Y Y}, V_{Y Z}$ and $V_{Z Z}$, respectively. The gradients values for particular derivatives have 

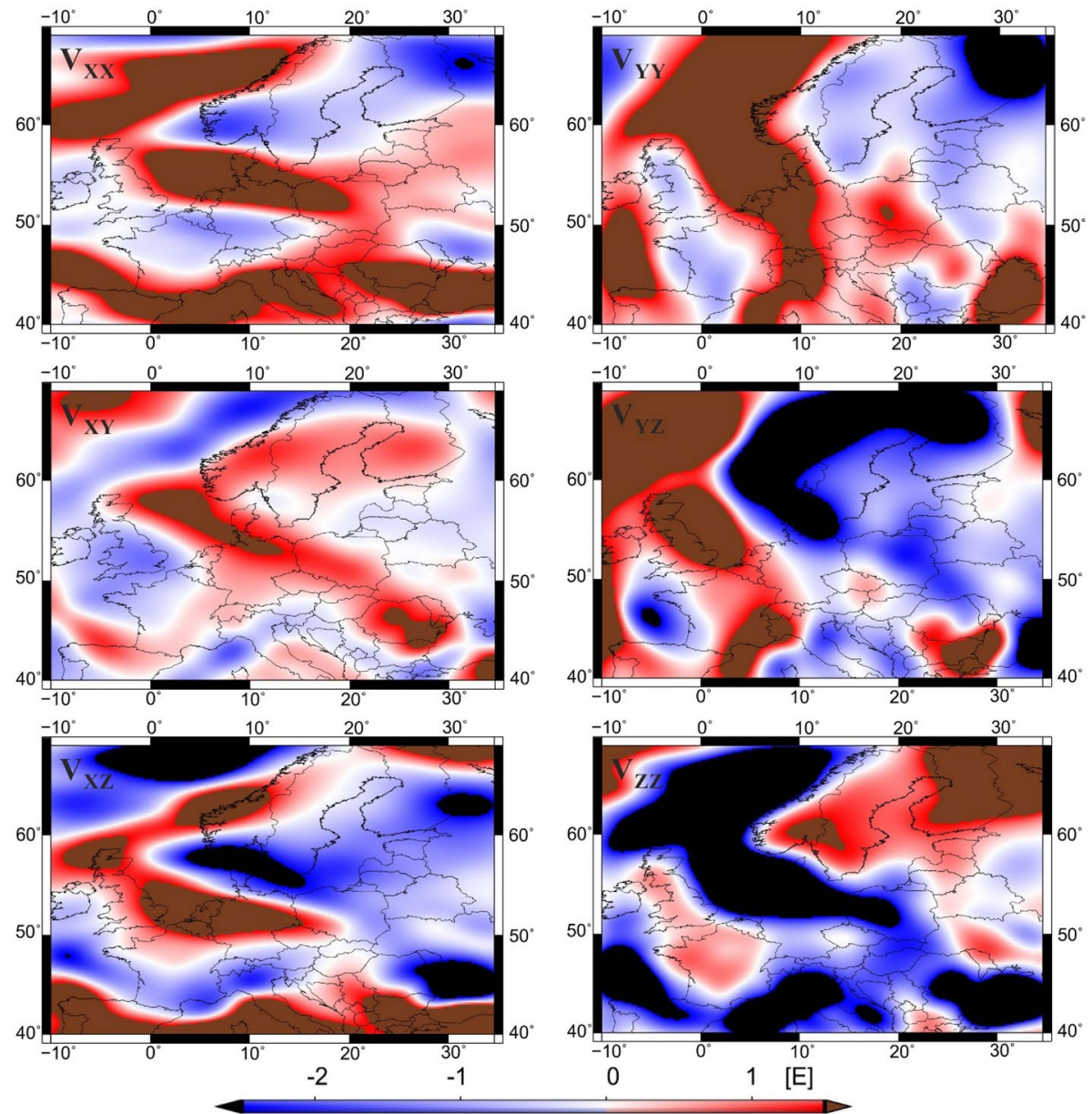

Fig. 2 Differences in the second potential derivatives for the studied area obtained from the GOCE mission data reduced by the topographic effect, sediments and Moho boundary depth between the density values from the PREM model and the 3D model. Values presented in the LNOF frame from altitude $255 \mathrm{~km}$, expressed in [E] (eotvos). The same scale as in Fig. 1 for comparative purposes should be noticed, despite different ranges of the models

Table 2 Differences in reduced GOCE gradients for two models: the tesseroid of densities from the Yegorova and Starostenko (2002) model as well as the generalized tesseroid with the densities from the PREM for the sediments and consolidated crust layers

\begin{tabular}{lrrrrrr}
\hline & $V_{X X}[\mathrm{E}]$ & $V_{X Y}[\mathrm{E}]$ & $V_{X Z}[\mathrm{E}]$ & $V_{Y Y}[\mathrm{E}]$ & $V_{Y Z}[\mathrm{E}]$ & \multicolumn{1}{c}{$V_{Z Z}[\mathrm{E}]$} \\
\hline Minimum & -2.540 & -2.348 & -5.285 & -4.974 & -6.390 & -12.062 \\
Maximum & 7.409 & 2.411 & 6.852 & 7.288 & 4.528 & 7.504 \\
Median & 0.494 & 0.071 & -0.399 & 0.388 & -0.395 & -0.847 \\
Standard deviation & 1.419 & 0.804 & 1.790 & 1.811 & 2.105 & 2.867 \\
\hline
\end{tabular}

Period from 1st of February 2010 to 11th of November 2013. Values presented in the LNOF frame, expressed in [E] (eotvos) 
increased more than 2-3 times in relation to the more reliable model, but ratio between components for both models remained quite similar.

When comparing the gradient differences between gain the $3 \mathrm{D}$ model values (parameters shown in Table 1) and the PREM model values we may notice that the discrepancies for some components decreased since the gradients from two models entail different methodology of density determination. Especially, the largest divergence shows significant differences in gradients for the sedimentary layer. In both models we used the density contrast with respect to the mean sea level. In the PREM model the densities were determined as a function of the Earth's radius, so the density for near-ground formations (down to a depth of $5 \mathrm{~km}$ ) have the same values as subsurface near mean sea level due to the low data diversity. This model supplied density contrast equal $1580 \mathrm{~kg} / \mathrm{m}^{3}$ for radius $6356-6371 \mathrm{~km}$. However, for sediments below $5 \mathrm{~km}$ deep, the density contrast increases significantly from 1580 to $1880 \mathrm{~kg} / \mathrm{m}^{3}$ for a depths greater than $10 \mathrm{~km}$. Such a huge differences in densities for the sedimentary layer are caused by large discrepancies in the distance to the Earth's center (radius of the particular spherical layer) in a given area, where densities change from 2600 to $2900 \mathrm{~kg} / \mathrm{m}^{3}$ (transition from sedimentary to consolidated crust) between radius of $6357-6356 \mathrm{~km}$ and from 2900 to over $3380 \mathrm{~kg} / \mathrm{m}^{3}$ (transition from crust to mantle) between the lengths of radius equal to $6347-6346 \mathrm{~km}$. The average value of the Earth's radius for sediments is $6359 \mathrm{~km}$. The density contrast (differences of $1580 \mathrm{~kg} / \mathrm{m}^{3}$ and $1880 \mathrm{~kg} / \mathrm{m}^{3}$ ) is clearly visible on differences of gravity gradients, which are shown in Fig. 2-a brown and red areas from the north-west to the south-east corner (for the $V_{Y Z}$ and $V_{Z Z}$ components dark blue and black belt on middle area) — area within the TESZ zone. The tesseroid density contrast values for sedimentary layer for the $3 \mathrm{D}$ model are up to $700 \mathrm{~kg} / \mathrm{m}^{3}$ for sediments above sea level and a maximum of $350 \mathrm{~kg} / \mathrm{m}^{3}$ for subsurface structures.

A similar ratio was obtained for the consolidated crust layer. PREM model is characterized by density contrast of c.a. $480 \mathrm{~kg} / \mathrm{m}^{3}$ for a depth from 20 to $32 \mathrm{~km}, 0.6$ to $2.70 \mathrm{~kg} / \mathrm{m}^{3}$ for a depth from 32 to $42 \mathrm{~km}$ and $780 \mathrm{~kg} / \mathrm{m}^{3}$ for deeper structures. As a consequence, we observed a difference in density contrast between separated layers, but less significant than for sediments. Still, for the 3D model, the densities are in the order of $0 \mathrm{~kg} / \mathrm{m}^{3}$ for $32 \mathrm{~km}$ depth and $130 \mathrm{~kg} / \mathrm{m}^{3}$ for the deepest areas. Obviously, this significant variation in density causes differences greater than $\pm 6 \mathrm{E}$ between both models. Figure 2 presents differences between gradients from 3D model and PREM-based model. We intentionally put the same scale as in Fig. 1 to show areas evidently differing from the 3D model values presented in brown and black for positive and negative values, respectively. Depending on the gravity component, we distinguished the largest variety in Scandinavia and the Balkan Peninsula, the TESZ zone and the surroundings of the Alps. There are also huge differences in ocean/ sea surface, with the exception of the shallow Baltic Sea (Fig. 2).

In Figs. 1 and 2, the significant variations in the gradient changes due to the variety of the geological structures in Europe are observed, resulting from tectonic processes. We can notice spatial changes of the gravity gradients (Figs. 1, 2), with extreme values correspond to small geological units, like the Alps, or the Carpathians, described in Sect. 3. The clearly distinguished black-blue and brown-red belts in Fig. 2 represent the TESZ zone. These extreme values of the difference of gradients from 3D model and reference PREM model, result from the general density representation in the PREM model, where density distribution is dependent just on the Earth's radius. The TESZ zone, clearly identified in Fig. 2 in $V_{X X}$ and $V_{Z Z}$ components by brown and black areas, is characterized by the Earth's radius differences ranging even $10 \mathrm{~km}$ due to the contact of two large platforms: Eastern European and Western European, where except the topography variations, the thickness of sedimental layer is much variable. For those areas, significant changes of $300 \mathrm{~kg} / \mathrm{m} 3$ in 
the density contrast were found. In Fig. 2 we observe gradient pattern quite similar to this shown in Fig. 1, where extreme values of gradients were also found in the area of North German-Polish Basin. They are caused by the difference in density between the PREM model of subsurface structures of the Eastern and Western European plates. Furthermore, our findings show a strong variation for the consolidated crust layer for most of the gradients, except for $V_{X Y}$ and $V_{X Z}$ shape components, due to the poor accuracy of their determination in high frequency MBW (Mueller 2003). The values of gradients clearly distinguish the main tectonic features and their deep structures, i.e. the North-Eastern Atlantic Margin, the Carpathians, the Alps, the Atlantic Ocean and subsurface (significant Moho's discontinuity depths) and structures of North-Eastern Poland. The small variation in the $V_{X Y}$ gradient results (pale colors in Fig. 1, small brown and black areas in Fig. 2) may come from a high filling with the gravity field model data (over $60 \%$ for the topocentric LNOF frame) (Rummel et al. 2011a).

The main conclusion of those numerical analysis is that the modeling of the gravity gradients should be more focused on defining the density values (precisely speaking its contrast) for sedimentary and consolidated crustal layers, than on the depth determination for both layers. It means, that increasing the accuracy of either density or depth models, will lead to rise of the reliability of the gradients, but not to the same extent. During calculations, we examined the dependence of changes in the gradients values with a variation of the density and depth parameters. Modifying density and depth by 5, 10 and $15 \%$ of their values lead to the difference in gradients from $0.05 / 0.1 \mathrm{E}$ for depth, while $0.1 / 0.2 \mathrm{E}$ for density already for 5\%. As shown in Fig. 2 change of the input density data may cause 2-3 times higher values of gradients when comparing to the 3D model. During calculations we obtained the similar proportion between the individual components values for the PREM model and the outcome shown in Fig. 1. More specifically, our findings proved that we will get larger variation in gradients if we use the less reliable density, than changing the density and thickness by the same percentage value.

Eshagh et al. (2016) in their research for the central part of the Eurasian plate exhibited the difference in the values of Moho boundary depth and density depending on the selected gravity field model. They used data for the sedimentary layer to the Moho border from global models, where the average density contrasts differ of about $50 \mathrm{~kg} / \mathrm{m}^{3}$ depending on used model, and the depth of the Moho border by about $10 \mathrm{~km}$. Here, we showed that changes in crust density and depth by $50 \mathrm{~kg} / \mathrm{m}^{3}$ and $10 \mathrm{~km}$ entail average changes in gradients values by $15 \%$ for density and $10 \%$ for depth. Tenzer and Novák (2013) calculated gradients for the entire globe including effects for topography/bathymetry, ice, sediments and impact of the structures of the crust to the Moho discontinuity. They used GOCO-03S model to compute global gradients and adopted the density contrast for all layers to a reference crust density equal to $2670 \mathrm{~kg} / \mathrm{m}^{3}$. Finally, they obtained the sensitivity values of radial components $(r r)$ from -1 to $+1.5 \mathrm{E}$, and horizontal components: $\varphi \varphi$ and $\lambda \lambda \pm 1 \mathrm{E}$ and $\pm 1.5 \mathrm{E}$, respectively. Our results cannot be directly compared, since for both layers we used a lower resolution model, i.e. $0.25^{\circ}$ per $0.25^{\circ}$ and $0.1^{\circ}$ per $0.1^{\circ}$, while Tenzer and Novák (2013) used the CRUST2.0 model with a 2 per 2 arc-deg resolution, which guarantees our results to have higher resolutions than the previous ones. Additionally, we used more variable model for Moho discontinuity depth in Europe area. All components were defined in the system of geocentric spherical coordinates, whereas our gradients were computed in topocentric frame, which provides some novelty to the previous studies.

In our results we revealed possibility of obtaining gravity gradients with high accuracy even to depth of the Moho discontinuity (several $\mathrm{km}$ ). Lieb et al. (2013) in their calculations computed GOCE gradients at $270 \mathrm{~km}$ height for Scandinavia area obtaining 
values $\pm 0.5 \mathrm{E}$ on the Earth's surface. In our calculations, we show that we can get the value of a similar order, modeling gradients to a certain depth in the Earth's interior. Bouman et al. (2013) estimated the accuracy of gradient values to each slice depth for area covered the North-Eastern Atlantic margin. They proved that gradients' determination equal to $\pm 1 \mathrm{E}$ in the topocentric LNOF frame from satellite altitude to $120 \mathrm{~km}$ depth is possible. They also identified significant differences between density contrast of geological structures (e.g. between the Atlantic Ocean and the Scandes it reaches $+1 \mathrm{E}$ for $V_{Y Y}$ ). They assessed the sensitivity of the GOCE gravity gradients to geological structures with respect to their thickness and density. Assuming a depth of 30-35 km they found gradients up to $\pm 1 \mathrm{E}$, using constant densities for each layer, whereas we get gradient changes from -2 to +1 E. However, we present specific gravitational gradient values to the assumed depth. In similar calculations to our study, Ebbing et al. (2014) set the gradient values for the density contrast, while for a reference depth of $32 \mathrm{~km}$, as opposed to us, they used the densities $-400 \mathrm{~kg} / \mathrm{m}^{3}$ and $+400 \mathrm{~kg} / \mathrm{m}^{3}$ below and above the reference level, respectively. We adopted a more accurate change of density for the consolidated crust layer, i.e. every $2 \mathrm{~km}$ below the reference level and $5 \mathrm{~km}$ above, assigning density values from 0 to $130 \mathrm{~kg} / \mathrm{m}^{3}$ for consolidated crust layer, obtaining gradient values varied from -2 to $+1 \mathrm{E}$. Within our calculations we also showed that differences of $20-30 \mathrm{~kg} / \mathrm{m}^{3}$ in tesseroid density contrasts for each layer cause gradient variations up to $2 \mathrm{E}$ on average.

As a result, we formed two different models: the 3D model with the highest possible reliability and another to do research on different parameters. Significant differences between both occur within the TESZ zone, for which the PREM model generalizes density too much. Usage of the 3D model allows for analysis of the contrast between the geological formations of the East European platform and the Paleozoic platform, characterized by a large thickness differences for sedimental layer.

\section{Summary}

Satellite gradiometry is a practical tool for studying the heterogeneity of the Earth. Satellite data are suitable for supplementing terrestrial measurements (Rudolph et al. 2002) and for providing high-degree gravity field models (Pail et al. 2011). Within this study, the GOCE data allowed us to reduce the gravity gradients (by means of Eötvös tensor components) to an assumed depth with a previous determination of the density and thickness of the subsurface structures, constituting the so-called "3D model".

In our calculations, we focused on determining gradients by forward modeling from the GOCE orbital altitude $(255 \mathrm{~km})$ to the depth of Moho discontinuity including effects from two layers of crust. During the study, we confirmed that gravity anomalies are generally more sensitive to density contrasts than their absolute values. By analyzing each layer separately, we noticed that the reduced gradients are mostly influenced by values set for sedimentary layer. In case of sediments, we obtained strong relation between density and changes of gradients in the considered area. For consolidated crust layer, we identified relatively high correlations between second derivative changes and depth of the Moho boundary. Additionally, we proved by numerical analysis that increasing the depth and density by the same percentage causes enhance changes in gradient values for the latter. It means that adding the same percentage values we will obtain changes in gradients values by $15 \%$ for density and $10 \%$ for depths. 
In the provided model, the changes in gradients revealed particular areas. In the NorthEastern Atlantic region, we observe strong regional relation between Baltic Shield and deep oceanic/sea crust, the most clearly seen for $V_{Y Y}$ and to a smaller extent for $V_{Z Z}$ components. We identified the TESZ zone (white stripe in Fig. 1. for $V_{X Y}$ and $V_{Y Z}$ components) and recognized also an area within the TESZ, which is represented clearly by extreme values (presented in red and blue colors) on $V_{X X}, V_{Y Y}$ and $V_{Z Z}$ components. Furthermore, we obtained positive values of all gradient (except $V_{Y Y}$ ) values for the Atlantic Ocean area.

The results show that forward modeling may be used for recognizing geological structures or mapping in previously undiscovered areas. Because of the sensitivity of the GOCE data to the geological structures with significant depth and/or density contrasts, these gradients can be used to improve e.g. the Moho model in not so well surveyed regions or for each of the models, where small amount of data is available.

Acknowledgements The authors would like to thank Jörg Ebbing for valuable advises on the processing of GOCE data and anonymous reviewers for their comments which helped to improve the manuscript. The ETOPO1 and the GECO models were obtained from http://icgem.gfz-potsdam.de/home on 14 November, 2017. This study was supported by the Project under the Ministry of National Defence Republic of Poland Program-Research Grant.

OpenAccess This article is distributed under the terms of the Creative Commons Attribution 4.0 International License (http://creativecommons.org/licenses/by/4.0/), which permits unrestricted use, distribution, and reproduction in any medium, provided you give appropriate credit to the original author(s) and the source, provide a link to the Creative Commons license, and indicate if changes were made.

\section{References}

Albertella A, Migliaccio F, Sanso F (2002) GOCE: the earth gravity field by space gradiometry. Celest Mech Dyn Astron 83:1-15. https://doi.org/10.1023/A:1020104624752

Arabelos D, Tscherning CC (1998) Calibration of satellite gradiometer data aided by ground gravity data. J Geodesy 72:617-625. https://doi.org/10.1007/s001900050201

Bagherbandi M, Eshagh M (2012) Crustal thickness recovery using an isostatic model and GOCE data. Earth Planets Space 64:1053-1057. https://doi.org/10.5047/eps.2012.04.009

Barthelmes F (2016) International centre for global earth models (ICGEM). J Geodesy Geod Handb 90(10):1177-1180. https://doi.org/10.1007/s00190-016-0948-z

Bobojc A (2016) Application of gravity gradients in the process of goce orbit determination. Acta Geophys 64(2):521-540. https://doi.org/10.1515/acgeo-2016-0004

Bouman J, Koop R (2003) Error assessment of GOCE SGG data using along track interpolation. Adv Geosci 1:27-32. https://doi.org/10.5194/adgeo-1-27-2003

Bouman J, Rispens S, Gruber T, Koop R, Schrama E, Visser P, Tscherning C, Veicherts M (2009) Preprocessing of gravity gradients at the GOCE high-level processing facility. J Geodesy 83(7):659-678. https ://doi.org/10.1007/s00190-008-0279-9

Bouman J, Fiorot S, Fuchs M, Gruber T, Schrama E, Tscherning CC, Veicherts M, Visser P (2011) GOCE gravitional gradients along the orbit. J Geodesy 85:791-805. https://doi.org/10.1007/s0019 0-011-0464-0

Bouman J, Ebbing J, Meekes S, Fattah RA, Fuchs M, Gradmann S, Haagmans R, Lieb V, Schmidt M, Dettmering D, Bosch W (2013) GOCE gravity gradient data for lithospheric modeling. Int J Appl Earth Obs Geoinf 35:16-30. https://doi.org/10.1016/j.jag.2013.11.001

Bouman J, Ebbing J, Fuchs M, Sebera J, Lieb V, Szwillus W, Haagmans R, Novak P (2016) Satellite gravity gradient grids for geophysics. Sci Rep 6:21050. https://doi.org/10.1038/srep21050

Braintenberg C (2015) Exploration of tectonic structures with GOCE in Africa and across-continents. Int J Appl Earth Obs Geoinf 35A:88-95. https://doi.org/10.1016/j.jag.2014.01.013

Dziewonski AM, Anderson DL (1981) Preliminary reference Earth model. Phys Earth Planet Inter 25(4):297-356. https://doi.org/10.1016/0031-9201(81)90046-7 
Ebbing J, Bouman J, Fuchs M, Lieb V, Haagmans R, Meekes JAC, Fattah RA (2013) Advancements in satellite gravity gradient data for crustal studies. Lead Edge 32:900-906. https://doi.org/10.1190/tle32 080900.1

Ebbing J, Bouman J, Fuchs M, Gradmann S, Haagmans R (2014) Sensitivity of GOCE gravity gradients to crustal thickness and density variations: Case study for the Northeast Atlantic Region. In: Marti U (ed) Gravity, geoid and height systems. International Association of Geodesy Symposia 141. Springer, Cham

Eshagh M (2008) Non-singular expressions for the vector and the gradient tensor of gravitation in a geocentric spherical frame. Comput Geosci 34:1762-1768. https://doi.org/10.1016/j.cageo.2008.02.022

Eshagh M, Hussain M, Tenzer R, Romeshkani M (2016) Moho density contrast in central Euroasia from GOCE gravity gradients. Remote Sens. https://doi.org/10.3390/rs8050418

Eshagh M, Ebadi S, Tenzer R (2017) Isostatic GOCE Moho model for Iran. J Asian Earth Sci 138:12-24. https://doi.org/10.1016/j.jseaes.2017.01.033

Fullea J, Afonso JC, Connolly JAD, Fernandez M, Garcia-Castellanos D, Zeyen H (2009) LitMod3D: an interactive 3-D software to model the thermal, compositional, density, seismological, and rheological structure of the lithosphere and sublithospheric upper mantle. Geochem Geophys Geosyst 10:Q08019. https://doi.org/10.1029/2009GC002391

Garcia RF, Bruinsma S, Massarweh L, Doornbos E (2016) Medium-scale gravity wave activity in the thermosphere inferred from GOCE data. J Geophys Res Space Phys 121(8):8089-8102. https://doi. org/10.1002/2016JA022797

Gilardoni M, Reguzzoni M, Sampietro D (2016) GECO: a global gravity model by locally combining GOCE data and EGM2008. Stud Geophys Geod 60(2):228-247. https://doi.org/10.1007/s11200-015-1114-4

Grad M, Tiira T (2009) The Moho depth map of the European plate. Geophys J Int 176(1):279-292. https:// doi.org/10.1111/j.1365-246X.2008.03919.x

Grombein T, Seitz K, Heck B (2013) Optimized formulas for the gravitational field of a tesseroid. J Seismol 16(2012):95-105. https://doi.org/10.1007/s10950-011-9251-X

Grombein T, Luo X, Seitz K, Heck B (2014) A wavelet-based assessment of topographic-isostatic reductions for GOCE gravity gradients. Surv Geophys 35:959-982. https://doi.org/10.1007/s10712-014-9283-1

Heyen H, Zorita E, von Storch H (1996) Statistical downscaling of monthly mean North Atlantic air-pressure to sea level anomalies in the Baltic Sea. Tellus Ser A Dyn Meteorol Oceanogr 48(2):312-323. https://doi.org/10.1034/j.1600-0870.1996.t01-1-00008.x

Laske G, Masters G, MA Z, Pasyanos M (2013) Update on CRUST1.0 - A 1-degree Global Model of Earth'sCrust. Geophysical Research Abstracts, 15, Abstract EGU2013-2658.

Lieb V, Bouman J, Dettmering D, Fuchs M, Schmidt M (2013) Combination of GOCE gravity gradients in regional gravity field modelling using radial basis functions. In: VIII Hotine Marussi symposium on mathematical geodesy, pp 101-108. https://doi.org/10.1007/1345_2015_71

Liu HX, Doornbos E, Nakashima J (2016) Thermospheric wind observed by GOCE: wind jets and seasonal variations. J Geophys Res Space Phys 121(7):6901-6913. https://doi.org/10.1002/2016JA022938

Marotta AM, Barzaghi R (2017) A new methodology to compute the gravitational contribution of a spherical tesseroid based on the analytical solution of a sector of a spherical zonal band. J Geodesy 91:12071224. https://doi.org/10.1007/s00190-017-1018-x

Mayer-Guerr T, Pail R, Gruber T, Fecher T, Rexer M, Schuh WD, Kusche J, Brockmann JM, Krasbutter I, Becker S, Eicker A, Schall J, Rieser D, Zehentner N, Baur O, Höck E, Hausleitner W, Maier A, Krauss S, Jäggi A, Meyer U, Prange L (2012) The new combined satellite only model GOCO03s. In: International symposium on gravity, geoid and height systems GGHS 2012, Venice, Italy

Meier U, Curtis A, Trampert J (2007) Global crustal thickness from neural network inversion of surface wave data. Geophys J Int 169(2):706-722. https://doi.org/10.1111/j.1365-246X.2007.03373.x

Molinari I, Morelli A (2011) EUcrust: a reference crustal model for the European Plate. Geophys J Int 185:352-364. https://doi.org/10.1111/j.1365-246X.2011.04940.x

Mueller J (2003) GOCE gradients in various reference frames and their accuracies. Adv Geosci 1:33-38. https://doi.org/10.15448/1920

Narkiewicz M, Petecki Z (2017) Basement structure of the Paleozoic Platform in Poland. Geol Q 61(2):502_520. https://doi.org/10.7306/gq.1356

Pail R, Bruinsma S, Migliaccio F, Foerste C, Goiginger H, Schuh WD, Hoeck E, Reguzzoni M, Brockmann JM, Abrikosov O, Veicherts M, Fecher T, Mayrhofer R, Krasbutter I, Sanso F, Tscherning CC (2011) First GOCE gravity field models derived by three different approaches. J Geodesy. https://doi. org/10.1007/s00190-011-0467-X

Peral M, Fernàndez M, Torne M (2018) Resolution test of GOCE satellite data applied to density anomalies at crustal and upper mantle levels. Geol Acta 16(1):93-105. https://doi.org/10.1344/geologicalacta2 018.16.1.6 
Reguzzoni M, Sampietro D (2014) GEMMA: an Earth crustal model based on GOCE satellite data. Int J Appl Earth Obs Geoinf 35A:31-43. https://doi.org/10.1016/j.jag.2014.04.002

Rudolph S, Kusche J, Ilk K (2002) Investigations on the polar gap problem in ESA's gravity field and steadystate ocean circulation explorer mission (GOCE). J Geodyn 33(1-2):65-74. https://doi.org/10.1016/ S0264-3707(01)00055-2

Rummel R (2011) GOCE-the gravity steady-state ocean circulation explorer preface. J Geodesy 85(11):747. https://doi.org/10.1007/s00190-011-0499-2

Rummel R, Horwath M, Yi W, Albertella A, Bosch W, Haagmans R (2011a) GOCE, satellite gravimetry and antarctic mass transports. Surv Geophys 32:643-657. https://doi.org/10.1007/s10712-011-9115-5

Rummel R, Yi W, Stummer C (2011b) GOCE gravitational gradiometry. J Geodesy 85(11):777-790. https:// doi.org/10.1007/s00190-011-0500-0

Sanchez-Reales JM, Vigo MI, Trottini M (2016) Ocean surface geostrophic circulation climatology and annual variations inferred from satellite altimetry and GOCE gravity data. Pure Appl Geophys 173(3):849-860. https://doi.org/10.1007/s00024-014-0981-x

Schuh WD (2003) The processing of band-limited measurements. Filtering techniques in the last square context and in the presence of data gaps. Space Sci Rev 108(1-2):67-78. https://doi.org/10.1023/A:10261 21814042

Shin YH, Shum CK, Braitenberg C, Lee SM, Na S-H, Choi KS, Hsu H, Park Y-S, Lim M (2015) Moho topography, ranges and folds of Tibet by analysis of global gravity models and GOCE data. Sci Rep 5:11681. https://doi.org/10.1038/srep11681

Siemes Ch (2017) Improving GOCE cross-track gravity gradients. J Geodesy 92:33-45. https://doi. org/10.10007/s00190-017-1042-X

Sjöberg LE, Bagherbandi M (2011) A method of estimating the Moho density contrast with a tentative application by EGM08 and CRUST2.0. Acta Geophys 59(3):502-525. https://doi.org/10.2478/s1160 0-011-0004-6

Tenze D, Braitenberg C, Sincich E, Mariani P (2014) Detecting the elevated crust to mantle section in the Kohistan-Ladakh Arc. Himalaya, from GOCE observations. Int Assoc Geodesy Symp Ser 141:299_ 307. https://doi.org/10.1007/978-3-319-10837-7_38

Tenzer R, Novák P (2013) Effect of crustal density structures on GOCE gravity gradient observables. Terres Atmos Ocean Sci 24(5):793-807. https://doi.org/10.3319/TAO.2013.05.08.01(T)

Tesauro M, Kaban MK, Cloetingh SAPL (2008) EuCRUST-07: a new reference model for the European crust. Geophys Res Lett 35(5):L05313. https://doi.org/10.1029/2007GL032244

Tsoulis D (2004) Spherical harmonic analysis of the CRUST 2.0 global crustal model. J Geodesy 78(12):7-11. https://doi.org/10.1007/s00190-003-0360-3

Uieda L, Barbosa V, Braitenberg C (2016) Tesseroids: forward-modeling gravitational fields in spherical coordinates. Geophysics. https://doi.org/10.1190/geo2015-0204.1

Yegorova TP, Starostenko VI (2002) Lithosphere structure of Europe and Northern Atlantic from regional three-dimensional gravity modeling. Geophys J Int 151(1):11-31. https://doi.org/10.1046/j.1365246X.2002.01728.x

Zhang Y, Wu Y, Yan J, Wang H, Rodriguez AAP, Qiu Y (2018) 3D inversion of full gravity gradient tensor data in spherical coordinate system using local north-oriented frame. Earth Planets Space 70:58. https ://doi.org/10.1186/s40623-018-0825-5

Znosko J (1977) Geological structure in zone of Tornquist-Teisseyre line between Baltic Sea and Swietokrzystkie-Gory. Zeitschirift fur Angewandte Geologie 23(9):439-444 